\title{
Establishment of BM-TRIZ Biomedical Inventive Principles and Design-thinking Methods for Innovative Design of Medical Devices Based on A New Polymeric Biomaterial Containing Polyvinyl Alcohol Foam via an Air-foaming Procedure
}

\author{
Huang $\mathrm{CC}^{1,2 *}$ \\ ${ }^{1}$ Department of Biomedical Engineering, Ming-Chuan University, Taiwan \\ ${ }^{2}$ PARSD Biomimetic and Biomedical Material Research Center, Taiwan
}

*Corresponding author: Ching-Cheng Huang, Department of Biomedical Engineering, MingChuan University, Taiwan, PARSD Biomimetic and Biomedical Material Research Center, Taiwan, Email: junas.tw@yahoo.com.tw

\section{Research Article}

Volume 4 Issue 2

Received Date: June 22, 2021

Published Date: July 02, 2021

DOI: $10.23880 /$ aabsc-16000162

\section{Abstract}

A new biomaterial containing polyvinyl alcohol foam with a fully open-cell microstructure would be designed and prepared via air-foaming procedure in this study. The resulting biomaterials might provide several functional properties for various clinic potential applications. Also, the resulting biomaterial containing polyvinyl alcohol foam could be employed to prepare a series of new medical device for the clinic potential applications. Further, a systematic design-thinking method for innovative design of medical device would be built up and provided. A series of new medical devices would be designed and obtained.

Keywords: Medical Device; Biomaterial; Open-cell microstructure; Design thinking Methods

Abbreviations: HPLC: High-performance Liquid Chromatography; DNPH: Dinitrophenylhydrazine.

\section{Introduction}

Medical innovation, designs and developments start with analyzing and identifying the market, the need of which is untapped or unmet or there is a more efficient way to address those clinic particular needs. The clinic needs would be anything that delivers a solution such as a new or better way of monitoring health, enhanced care delivery solutions, materials, devices or technologies to deliver better administration and treatments that supports health. For these reasons, numerous materials would be proposed, modified and used for clinic applications such as synthetic materials and natural materials [1-14]. In usual, the materials of medical dressings must provide water absorption, porosity, mechanical strength, water permeability, and/or breathability to satisfy clinic needs. In this study, a series of designed biomaterials containing polyvinyl alcohol foam were designed and prepared by using a clean air-foaming process without an addition of starch to build up a special fully open-cell microstructure. The process without any addition of starch could avoid fungi contaminations. A systematic method containing biomedcial TRIZ (BM-TRIZ) inventive principles and a new design-thinking method could be built up and applied in this study. The variables in TRIZ are tied up with engineering problems, although TRIZ is powerful enough to be a universal problem solving method [15-19]. However, development and design of medical devices was limited by using the TRIZ method. In order to design a new medical device with good potentials in clinic applications, a 
systematic design-thinking method must be established.

In this study, methodology for innovative design of new medical derives based on guide information of TRIZ inventive principles and new design-thinking routines would be established. A new designed biomaterial containing polyvinyl alcohol foam with a fully open-cell microstructure would be prepared. A series of new medical devices based on the resulting biomaterial containing PVA foam could be designed by using the resulting systematic method combined BM-TRIZ inventive principles and new design-thinking routines.

\section{Materials and Methods}

\section{Materials}

Designed polyvinyl alcohol foam could be prepared in this work by using a designed super clean air-foaming process and the medical grade Cenefom materials (PARSD Pham. Tech. Co.).

\section{Water Permeability}

The water permeability of the resulting polyvinyl alcohol foam dressings could be determined by following ASTM D4491 (standard test methods for water permeability).

\section{Residual Formaldehyde}

The high-performance liquid chromatography (HPLC) analysis and 2,4-dinitrophenylhydrazine(DNPH) was employed for determination of residual formaldehyde which follows ISO17226-1 and ISO 10993-12:2012. While there are no standardized methods available at present for testing absorbents, the following is a suggested protocol. Determine the volume of extraction vehicle that each $0.1 \mathrm{~g}$ or $1.0 \mathrm{~cm} 2$ of material absorbs such as PVA foam as an additional corrected volume. Then, in performing the material extraction, add the additional corrected volume to each $0.1 \mathrm{~g}$ or $1.0 \mathrm{~cm}^{2}$ in an extraction mixture as stated in ISO 10993-12:2012 for preparation of PVA foam samples.

\section{Results and Discussion}

\section{Preparation of New Biomaterial Containing Polyvinyl Alcohol Foam}

In this work, a new biomaterial containing polyvinyl alcohol foam was obtained, purified, and characterized. Low residual formaldehyde content $(<10 \mathrm{ppm})$ was determined. SEM morphology of the resulting biomaterial containing polyvinyl alcohol foam was determined. The resulting biomaterial containing polyvinyl alcohol foam with a fully open-cell microstructure was observed as shown in
Figure 1. The diameter of the open cell in the fully opencell microstructure could be observed in a range between $100 \mu \mathrm{m}$ and $500 \mu \mathrm{m}$. The fully open-cell microstructure would provide high water permeability and high water absorption. The resulting PVA foam with higher water permeability than $85 \%$ was obtained. The high water absorption of the resulting biomaterial could be obtained ( $>13$ times).

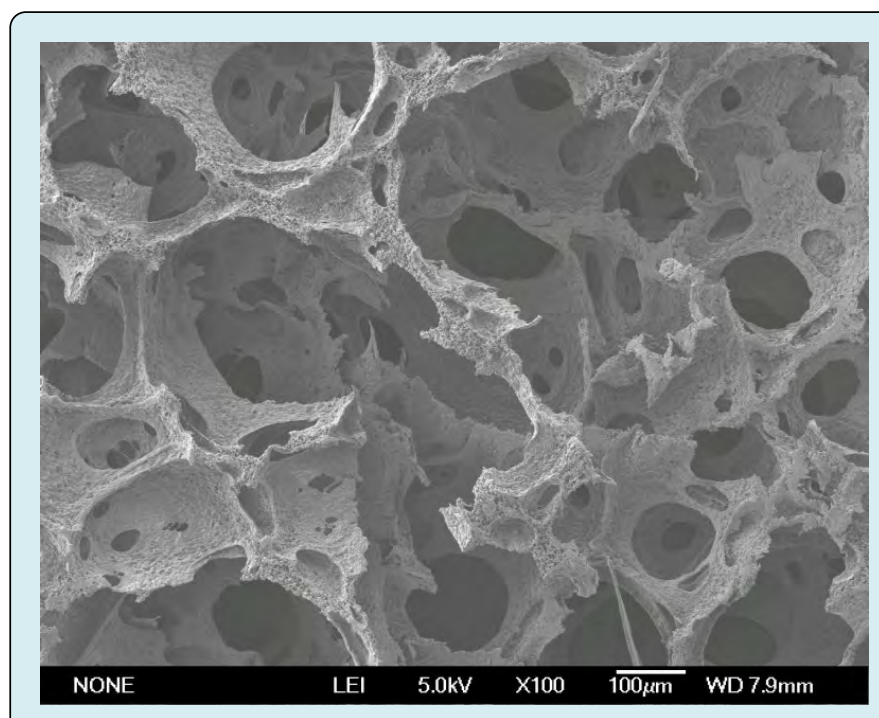

Figure 1: SEM morphology of the new polyvinyl alcohol foam material via air-foaming process(x100).

\section{BM-TRIZ Biomedical Inventive Principles and Design-Thinking Methods for an Innovative Design of New Medical Devices}

In this study, the 40 principles of TRIZ could be employed to build up BM-TRIZ biomedical inventive principles and design-thinking methods for an innovative design of new medical devices such as segmentation(1), extraction(2), local quality(3), asymmetry(4), merging(5), universality(6), Russian dolls(7), anti-weight(8), preliminary anti-action(9), preliminary action(10), beforehand cushioning(11), equipotentiality(12), Theotherwayround(13), spheroidality/ curvature(14), dynamics(15), partial or excessive actions(16), another dimension(17), mechanical vibration(18), Periodic action(19), continuity of useful action(20), skipping(21), blessing in disguise(22), feedback(23), intermediary(24), self-service(25), copying(26), cheap short-lived objects(27), mechanics substitution(28), pneumatics and hydraulics(29), flexible shells and thin films(30), porous materials(31), colour changes(32), homogeneity(33), discarding and recovering(34), parameter changes(35), phase transitions(36), thermal expansion(37), strong oxidants(38), inert atmosphere(39) and composite materials(40).

A series of new medical devices based on the resulting PVA foam materials were designed for new clinic potential 
applications depending on some selected BM-TRIZ biomedical inventive principles as shown in Tables 1-6. The different features such as space conversion features, time conversion features, subject transformation features, force conversion features, material or form conversion features, and environmental conversion features were considered for inventive designs of new medical devices as designthinking routines. Table 1 showed new designs of medical devices based on PVA foam depending on selected BM-TRIZ inventive principles such as $1,3,4,7,14$ and 17 with space conversion features. For example, the shape of nasal packing product with PVA foam was changed from a symmetrical membrane to an asymmetrical nasal packing product for anatomical reasons as shown in Table 1 (MD4, selected BMTRIZ inventive principle 4).

\begin{tabular}{|c|c|c|c|}
\hline \multicolumn{3}{|c|}{ BM-TRIZ inventive principles } & New Design for clinic application \\
\hline New design number & \multicolumn{2}{|c|}{ Segmentation } & \\
\hline MD1 & 1 & Local Quality & \\
\hline MD4 & 3 & Asymmetry & \\
\hline MD7 & 4 & Russian dolls & \\
\hline MD14 & & Spheroidality - Curvature & \\
\hline MD17 & 14 & Another dimension & \\
\hline
\end{tabular}

Table 1: New designs of medical devices based on PVA foam depending on selected BM-TRIZ inventive principles with space conversion features.

Table 2 showed new designs of medical devices based on PVA foam depending on selected BM-TRIZ inventive principles such as $9,10,11,15,19,20$, and 21 with time conversion features. Changing the continuous suction module to a periodic suction module, NPWT dressings with periodic suction could be obtained (MD11 in Table 2, selected BM-TRIZ inventive principle 11).

\begin{tabular}{|c|c|c|c|}
\hline \multicolumn{2}{|c|}{ Time conversion } \\
\hline New design number & \multicolumn{2}{|c|}{ Selected BM-TRIZ inventive principles } & New Design for clinic application \\
\hline MD9 & 9 & Preliminary anti-action & \\
\hline MD10 & 10 & Preliminary action & \\
\hline MD11 & 11 & Beforehand cushioning & \\
\hline
\end{tabular}




\begin{tabular}{|l|l|l|l|}
\hline MD15 & 15 & & Dynamics \\
\hline MD19 & 19 & Continuity of Useful Action \\
\hline MD20 21 & 20 & Skipping \\
\hline
\end{tabular}

Table 2: New designs of medical devices based on PVA foam depending on selected BM-TRIZ inventive principles with Time conversion features

Table 3 showed new designs of medical devices based on PVA foam depending on selected BM-TRIZ inventive principles such as $2,5,6,13,22,23,24,25,26,27,28$, and 34 with subject transformation features. For example, the medical device of eye drain was obtained by singling out an only necessary part of a LASIK ring as shown in Table 3 (MD2). Low cross-linked PVA foam with a shape of nasal cavity was employed as a medical degradable ENT dressing (MD13 in Table 3, selected BM-TRIZ inventive principle 13).

\begin{tabular}{|c|c|c|c|}
\hline \multicolumn{3}{|c|}{ Subject Transformation } \\
\hline New design number & \multicolumn{2}{|c|}{ Selected BM-TRIZ inventive principles } & New Design for clinic application \\
\hline MD2 & 2 & Extraction & Merging \\
\hline MD5 & 5 & Multiple functions & \\
\hline MD6 & 13 & The other way round & \\
\hline MD13 & 22 & Blessing in disguise & \\
\hline MD23 & & \\
\hline MD24 & 23 & Feedback & \\
\hline MD25 & 24 & Sntermediary & \\
\hline
\end{tabular}




\begin{tabular}{|c|c|c|c|}
\hline MD 26 & 26 & Copying & \\
\hline MD27 & 27 & Cheap short-lived objects & \\
\hline MD 28 & 28 & Mechanics substitution & \\
\hline MD34 & 34 & Discarding and recovering & \\
\hline
\end{tabular}

Table 3: New designs of medical devices based on PVA foam depending on selected BM-TRIZ inventive principles with subject transformation features

Table 4 showed new designs of medical devices based on PVA foam depending on selected BM-TRIZ inventive principles such as $8,12,16,18$, and 29 with force conversion features. For example, the medical device of NPWT dressings was designed by introducing a continuous suction module, a suction tube, and a NPWT dressing based on the resulting biomaterial containing PVA foam as shown in Table 4(MD12, selected BM-TRIZ inventive principle 12).

\begin{tabular}{|c|c|c|c|}
\hline \multicolumn{2}{|c|}{ Force conversion } \\
\hline New design number & \multicolumn{2}{|c|}{ Selected BM-TRIZ inventive principles } & New Design for clinic application \\
\hline MD8 & 8 & Anti-weight & \\
\hline MD12 & 12 & Equipotentiality & \\
\hline MD16 & 16 & Partial or excessive actions & \\
\hline MD18 & 18 & Mechanical vibration & \\
\hline MD29 & & & \\
\hline
\end{tabular}

Table 4: New designs of medical devices based on PVA foam depending on selected BM-TRIZ inventive principles with force conversion features

Table 5 showed new designs of medical devices based on PVA foam depending on selected BM-TRIZ inventive principles such as $31,32,33,35,36,37$, and 40 with material or form conversion features. For example, the chitosan oligosaccharide modified cross-linked polyvinyl alcohol complex foam (COS/ cPVACF) dressings was designed as a new medical device (MD40 in Table 5, selected BM-TRIZ inventive principle 40). 


\begin{tabular}{|c|c|c|c|}
\hline \multicolumn{3}{|c|}{ Material or form conversion } \\
\hline New design number & \multicolumn{3}{|c|}{ Selected BM-TRIZ inventive principles } \\
\hline MD31 & 31 & Porous materials \\
\hline MD32 & 32 & Colour changes & \\
\hline MD33 & 33 & Homogeneity & \\
\hline MD35 & 35 & Parameter changes & \\
\hline MD36 & 36 & Phase transitions & \\
\hline MD40 & 37 & Thermal expansion & \\
\hline
\end{tabular}

Table 5: New designs of medical devices based on PVA foam depending on selected BM-TRIZ inventive principles with material or form conversion features.

Table 6 showed new designs of medical devices based on PVA foam depending on selected BM-TRIZ inventive principles such as 38 and 39 with environmental conversion features. For example, strong oxidant (HClO3)-containing
PVA foam with a big size was considered as a new medical device of wet NPWT dressings (MD38 in Table 6, selected BM-TRIZ inventive principle 38).

\begin{tabular}{|c|c|c|}
\hline \multicolumn{3}{|c|}{ Environmental conversion } \\
\hline New design number & \multicolumn{3}{|c|}{ Selected BM-TRIZ inventive principles } & New Design for clinic application \\
\hline \multirow{2}{*}{ MD38 } & 38 & Strong oxidants
\end{tabular}

Table 6: New designs of medical devices based on PVA foam depending on selected BM-TRIZ inventive principles with environmental conversion features.

In this study, an innovative medical device designthinking procedure was established as shown in Figure 2. First, all properties of new biomaterials must be characterized for clinic potential applications. The proposal design must focus on targeting clinic needs. The selected biomaterial-TRIZ (BM-TRIZ) inventive principles could be built up and considered for specific designs of new medical devices to satisfy targeting clinic needs. The targeting model devices could be obtained as listed in Tables 3 6. Finally, summary of technical documentation (STED) information could be employed for risk assessments. A series of novel medical devices could be obtained for clinic needs (Figure 
2). Also market information and patent information could be further considered for market reasons.

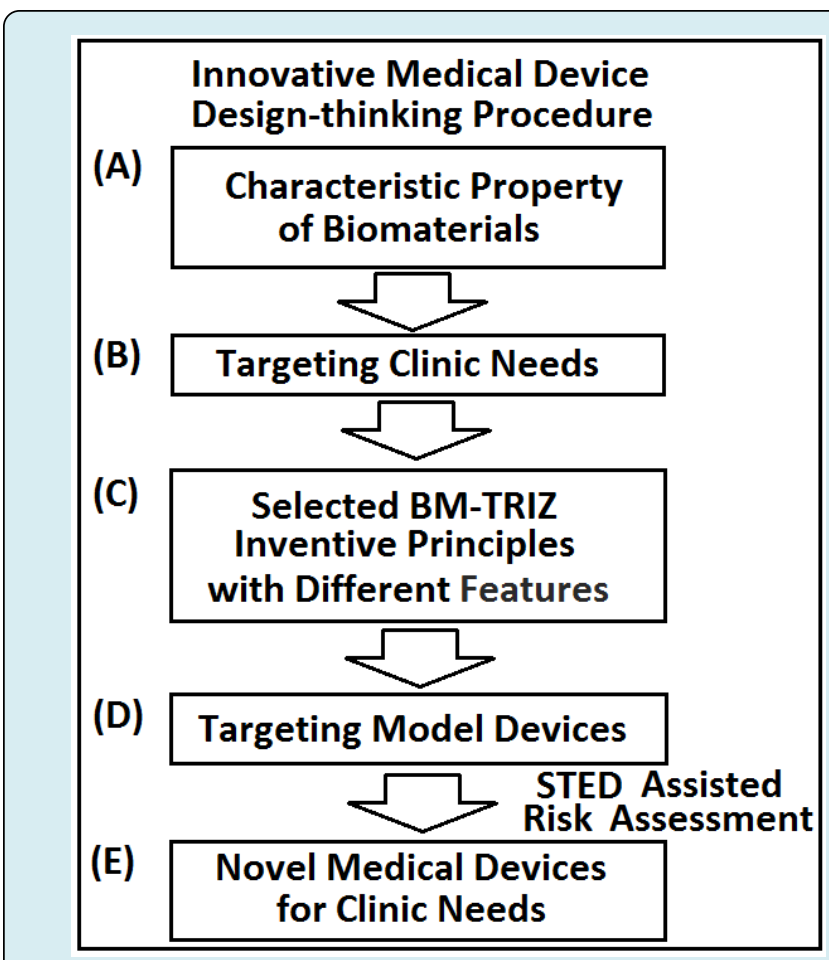

Figure 2: Innovative Medical device design-thinking procedure in this work.

\section{Conclusion}

A kind of new biomaterial containing polyvinyl alcohol foam was successfully designed and prepared via air-foaming procedure in this work. The resulting biomaterial containing polyvinyl alcohol foam could be employed to prepare a series of new medical device for various clinic applications. Establishment of BM-TRIZ biomedical inventive principles and a design-thinking method for innovative design of medical device was achieved. The systematic design method of PVA foam for the clinic applications of medical dressings could be used to demonstrate the capability of the proposed method. Importantly, summary of technical documentation (STED) information was suggested to be employed for references assisted risk assessments. A series of new medical devices were designed by using the resulting BM-TRIZ biomedical inventive principles and the design-thinking method to satisfy various clinic needs.

\section{Acknowledgement}

Authors would like to acknowledge the PARSD Pharmaceutical Technology Consultants Ltd Company and Cenefom Corp. for their financial and technical support.

\section{References}

1. Lieberman JR, Daluiski A, Stevenson S, Wu L, McAllister $P$, et al. (1999) The effect of regional gene therapy with bone morphogenetic protein-2-producing bone-marrow cells on the repair of segmental femoral defects in rats. J Bone Joint Surg Am 81(7): 905-917.

2. Seo Y, Jung Y, Kim SH (2018) Decellularized heart ECM hydrogel using supercritical carbon dioxide for improved angiogenesis. Acta Biomaterialia 67: 270-281.

3. Tsezou A (2014) Osteoarthritis year in review 2014: genetics and genomics. Osteoarthritis Cartilage 22(12): 2017-2024.

4. Huang CC, Liu CY, Huang CY, Liu HW (2014) Carbodiimide crosslinked and biodegradation-controllable small intestinal submucosa sheets. Biomed Mater Eng 24(6): 1959-1967.

5. Liaw DJ, Huang CC, Lee WF, Borbély J, Kang ET (1997) Synthesis and Characteristics of the Poly(carboxybetaine) $\mathrm{s}$ and the Corresponding Cationic Polymers, J Polym Sci Part A: Polym Chem, 35(16): 3527-3536.

6. Liaw DJ, Huang CC, Sang HC, Kang ET (1999) Intramolecular Hydrophobic Aggregation of Amphiphilic Polysulfobetaine with Various Hydrophobic Groups in Aqueous Solution. Langmuir 15(16): 5204-5211.

7. Chaw JR, Liu HW, Shih YC, Huang CC (2015) New Designed Nerve Conduits with Porous Ionic Cross-linked Alginate/Chitisan Structure for Nervous Regeneration. J Biomed Mater Eng 26(1): 95-102.

8. Alluri R, Song X, Bougioukli S, Pannell W, Vakhshori $\mathrm{V}$, et al. (2019) Regional gene therapy with 3D printed scaffolds to heal critical sized bone defects in a rat model. Biomed Mater Res A 107(10): 2174-2182.

9. Vogel KG \& Trotter JA (1987) The Effect of Proteoglycans on the Morphology of Collagen Fibrils Formed in Vitro. Coll Relat Res 7(2): 105-114.

10. Theocharis AD, Skandalis SS, Gialeli C, Karamanos NK (2016) Extracellular matrix structure. Advanced Drug Delivery Reviews 97: 4-27.

11. Guo JL, Kim YS, Mikos AG (2019) Biomacromolecules for Tissue Engineering: Emerging Biomimetic Strategies. Biomacromolecules 8: 2904-2912.

12. Rothrauff BB, Coluccino L, Gottardi R, Ceseracciu L, Scaglione S, et al. (2018) Efficacy of thermoresponsive, photocrosslinkable hydrogels derived from decellularized tendon and cartilage extracellular matrix 
for cartilage tissue engineering, J Tissue Eng Regen Med 12(1): 159-170.

13. Rothrau BB, Yang G, Tuan RS (2017) Tissue-specific bioactivity of soluble tendon-derived and cartilagederived extracellular matrices on adult mesenchymal stem cells. Stem Cell Res Ther 8: 133.

14. Woodfield TB, Malda J, Wijn J, Péters F, Riesle J, et al. (2004) Design of porous scaffolds for cartilage tissue engineering using a three-dimensional fiber-deposition technique. Biomaterials 25(18): 4149-4161.

15. Mayda M, Borklu HR(2014) Development of an innovative conceptual design pro-cess by using Pahl and Beitz's systematic design, TRIZ and QFD. Journal of Advanced Mechanical Design, Systems, and Manufacturing 8(3): 1-12.
16. Mann DL (2003) Better technology forecasting using systematic innovation methods. Technology Forecast Soc 70(8): 779-795.

17. Ishihama M (2003) Training students on the TRIZ method using a patent database. International Journal of Technology Management 25(6-7): 568-578.

18. Abdala LN, Fernandes RB, Ogliari A, Lower M, Feldhusen J (2017) Creative contributions of the methods of inventive principles of triz and biotriz to problem solving. Journal of Mechanical Design 139(8): 1-9.

19. Borgianni Y, Cardillo A, Cascini G, Rotini F (2011) Systematizing new value proposition through a TRIZbased classification of functional features. Procedia Engineering 9: 103-118. 